\title{
Endoscopic management of a relapsing hepatic hydatid cyst with intrabiliary rupture: A case report and review of the literature
}

\author{
Andreas Manouras MD PhD, Michael Genetzakis MD, Pantelis T Antonakis MD, Emmanuel Lagoudianakis MD, \\ Michael Pattas MD, Artemisia Papadima MD, Panagiotis Giannopoulos MD, Evangelos Menenakos MD
}

\begin{abstract}
A Manouras, M Genetzakis, PT Antonakis, et al. Endoscopic management of a relapsing hepatic hydatid cyst with intrabiliary rupture: A case report and review of the literature. Can J Gastroenterol 2007;21(4):249-253.
\end{abstract}

Hydatid disease, although endemic mostly in sheep-farming countries, remains a public health issue worldwide, involving mainly the liver. Intrabiliary rupture is the most frequent complication of the hepatic hydatid cyst. Endoscopy is advocated, preoperatively, to alleviate obstructive jaundice caused by intracystic materials after a frank rupture and is also a useful and well-established adjunct in locating postoperative biliary fistulas.

Endoscopic retrograde cholangiography with sphincterotomy has been successful as the sole and definitive means of treatment of intrabiliary ruptured hydatid cysts. A case of an elderly woman with frank rupture is presented, where the rupture was definitively managed endoscopically in conjunction with sphincterotomy to remove the intrabiliary obstructive daughter cysts and to achieve decontamination of the biliary tree.

Endoscopic retrograde cholangiography provided an excellent diagnostic and therapeutic modality in the present case and, thus, it should be considered as definitive treatment in similar cases especially if surgical risk is anticipated to be high.

Key Words: Endoscopic treatment; Hydatid disease; Intrabiliary rupture
La prise en charge endoscopique d'une récidive de kyste hydatide hépatique avec rupture intrabiliaire : Un rapport de cas et une analyse bibliographique

\begin{abstract}
Bien que principalement endémique dans les pays où se pratique l'élevage du mouton, la maladie hydatique, qui s'attaque surtout au foie, reste un problème de santé publique partout dans le monde. La rupture intrabiliaire est la principale complication du kyste hydatide hépatique. L'endoscopie est préconisée avant l'opération pour éviter une jaunisse obstructive causée par des matières intrakystiques après une rupture franche et elle constitue une mesure auxiliaire utile et bien établie pour repérer des fistules biliaires après l'opération.

La cholangiographie rétrograde endoscopique accompagnée d'une sphinctérotomie est le seul mode de traitement des ruptures de kystes hydatides biliaires. Le cas d'une femme âgée ayant une rupture franche est présenté, où la rupture a été résolue par voie endoscopique conjointement avec une sphinctérotomie pour supprimer les kystes fils obstructifs intrabiliaires et pour obtenir une décontamination de l'arbre biliaire.

La cholangiographie rétrograde endoscopique a constitué un diagnostic et une modalité thérapeutique de premier ordre dans le cas présent. Par conséquent, il faut l'envisager comme traitement définitif dans des cas similaires, surtout si le risque chirurgical anticipé est élevé.
\end{abstract}

F chinococcal disease is a parasitic zoonosis with humans Ebeing the intermediate host. Echinococcus granulosus, causing cystic hydatid disease, and Echinococcus multilocularis, causing alveolar hydatid disease, are of the most medical importance, infecting humans by entering the gastrointestinal tract. Although it can be encountered in any organ, echinococcosis most commonly affects the liver (50\% to $70 \%$ ) and the lungs ( $10 \%$ to $15 \%)$ (1).

Hepatic hydatid disease usually runs asymptomatically, while clinical features, if present, are usually due to complications that supervene (1). The most commonly encountered complication, occurring in almost $50 \%$ of cases on admission, is rupture into the biliary tree with secondary biliary obstruction by intracystic material or cholangitis $(2,3)$. Intracystic or subphrenic abscess formation after intraperitoneal rupture, as well as rupture into the bronchial tree, is less frequent (1,4-6).

In the case of intrabiliary rupture, endoscopic retrograde cholangiography (ERC) in conjunction with endoscopic sphincterotomy (ES) achieves decompression of the biliary tree from intracystic debris and prevents recurrence of the obstructive jaundice by ES (4-8). The endoscopic method was applied as the sole means for the treatment of a female patient with frank intrabiliary rupture of a hydatid hepatic cyst, and produced impressive curative results.

\section{CASE PRESENTATION}

An 81-year-old woman was admitted to Hippocrateion Hospital in Athens, Greece, suffering from high fever, rigors and jaundice. Her past medical history was insignificant except for an echinococcal cyst of the left hepatic lobe that was diagnosed and surgically treated during World War II. Physical examination revealed tachycardia and mild, right, upper quadrant abdominal tenderness. Her initial workup showed white blood cell counts of $41 \times 10^{9} / \mathrm{L}$ (where $96 \%$ of the cells were polymorphonuclear), hemoglobin levels of $106 \mathrm{~g} / \mathrm{L}$, platelet counts of $231 \times 10^{9} / \mathrm{L}$, creatinine levels of $185.6 \mu \mathrm{mol} / \mathrm{L}$, urea nitrogen levels of $7.14 \mathrm{mmol} / \mathrm{L}$, aspartate aminotransferase levels of $137 \mathrm{U} / \mathrm{L}$, alanine aminotransferase levels of $90 \mathrm{U} / \mathrm{L}$, gamma-glutamyl transpeptidase levels of $414 \mathrm{U} / \mathrm{L}$, alkaline 


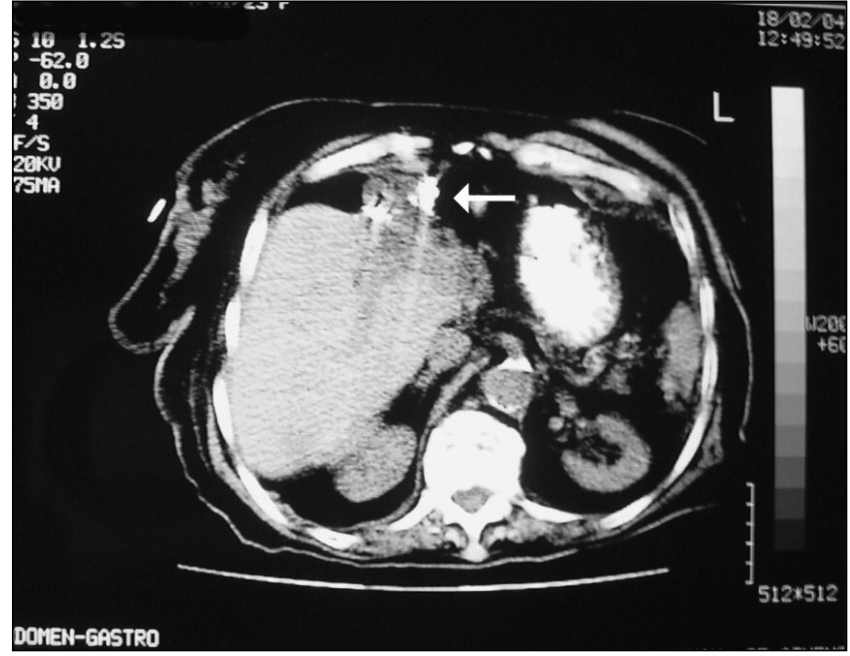

Figure 1) Abdominal computed tomography scan revealing an irregular mass (arrow) with partial calcification of the wall in segment IV of the common bile duct

phosphatase levels of $310 \mathrm{U} / \mathrm{L}$, total bilirubin levels of $130 \mu \mathrm{mol} / \mathrm{L}$ and direct bilirubin levels of $80.4 \mu \mathrm{mol} / \mathrm{L}$. The indirect hemagglutination test for Echinococcus species was negative. Upper abdominal ultrasound showed a multiloculated cyst in the left liver lobe, and dilation of the extrahepatic biliary ducts with hyperechoic material in the common bile duct (CBD). An abdominal computed tomography (CT) scan revealed an irregular cystic mass, $6 \mathrm{~cm}$ in diameter, in segment IV (Figure 1), and marked dilation of the CBD. Thus, acute cholangitis was diagnosed and intrabiliary rupture of a relapsing hydatid cyst was highly suspected to be the cause. Proper antibiotic treatment was intravenously administered. The patient's general condition, as well as physical signs and laboratory values, rapidly improved within $24 \mathrm{~h}$.

ERC revealed a dilated choledochal duct with angular configuration and a free-floating cystic mass. Biliary tree communication with the cystic remnant was not demonstrated (Figure 2). ES was performed and the daughter cyst was extracted with a Fogarty catheter. Hypertonic saline was administered through a nasobiliary catheter for $5 \mathrm{~min}$ to decontaminate the biliary tree. The patient had an uncomplicated recovery and was discharged on the second day post-ERC. The patient denied any further treatment with anthelminthic medication, and remains asymptomatic 36 months after the admission.

\section{DISCUSSION}

Hepatic hydatid disease after a long asymptomatic course becomes symptomatic in an unknown percentage of patients. Hydatid cysts grow at a variable rate and stabilize, and may become calcified, while others may collapse and completely resolve (9). The clinical course is long and even after surgical treatment, decontamination is difficult to achieve.

Becoming symptomatic may be due to pressure exertion of the cyst on the liver parenchyma, or rupture into surrounding tissues (10). Intrabiliary rupture is the most frequent complication, representing approximately $50 \%$ of cases on admission. However, the percentage increases up to $80 \%$ to $90 \%$, if the cases of small subclinical cystobiliary communications are included. These cases, which are frequently overlooked pre- and

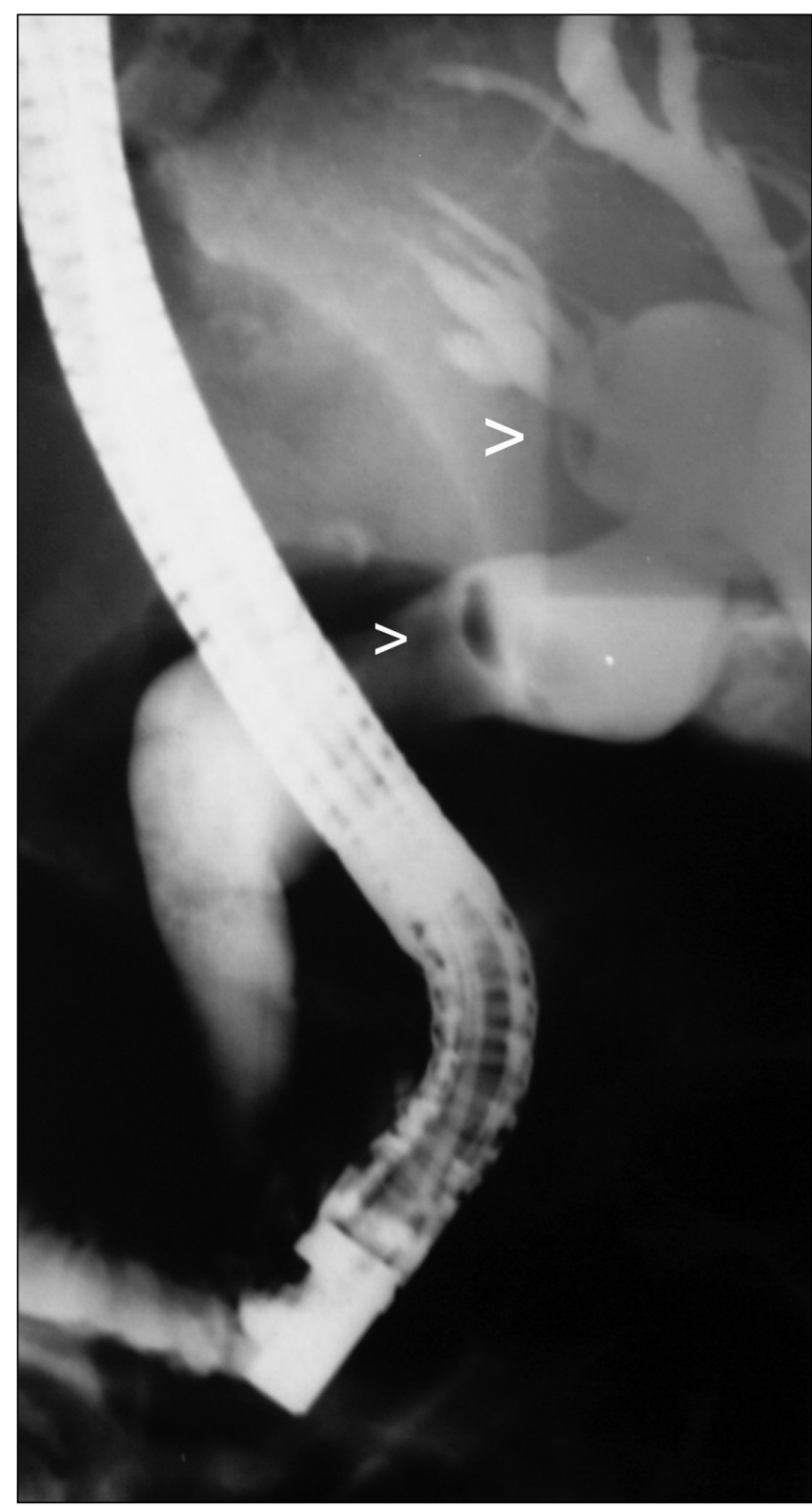

Figure 2) Endoscopic retrograde cholangiography revealing a markedly dilated choledochal duct with angular configuration and a free-floating cystic mass (arrowheads). Communication of the biliary tree with the cystic remnant was not demonstrated

intraoperatively, may cause external cystobiliary fistulas postoperatively (5). The mechanism of intrabiliary rupture seems to be that of entrapment of small bile duct radicles in the pericyst, which due to increased intracystic pressure undergo atrophy resulting in rupture $(5,11)$. Following cyst enlargement, communication with larger ducts is established (12). Most liver hydatid cysts that remain symptom free for long periods of time are mistakenly considered to be at low risk for rupture (13).

Intrabiliary rupture mainly occurs in centrally localized cysts, while an intracystic $\mathrm{H}_{2} \mathrm{O}$ pressure of up to $80 \mathrm{~cm}$ is also a predisposing factor (10). Intrabiliary rupture occurs either as an occult rupture, in which only cystic fluid is drained to the biliary tree, or as a frank rupture with overt passage of intracystic material to the biliary tract (14). The reported frequency for occult rupture is $10 \%$ to $37 \%$, and $3 \%$ to $17 \%$ for frank rupture $(4-6,15,16)$. In frank rupture, cystic material, even daughter 
cysts, are allowed to pass into the biliary tree causing septic contamination of the mother cyst, obstructive jaundice (in two-thirds of cases) or cholangitis (6). On the other hand, occult rupture has rather minor consequences because obstruction occurs in only $5 \%$ to $10 \%$ of cases because only fluid, scolices, hooks, small brood capsules and cystic wall fragments can pass the small-sized bile radicles reaching the biliary tree (17). Intrabiliary rupture occurs in $55 \%$ to $60 \%$ of cases into the right hepatic duct, $25 \%$ to $30 \%$ into the left hepatic duct, $8 \%$ to $11 \%$ into the hepatic duct junction, CBD or cystic duct, and $5 \%$ to $6 \%$ perforate into the gallbladder $(4,18,19)$. Spontaneous recovery rate after rupture is reported to be approximately $25 \%$; in the remaining cases, persistent obstructive jaundice, cholangitis or septicemia may develop with mortality ranging from $30 \%$ to $50 \%(4,10,18)$. Obstructive jaundice, caused by the impact of intracystic material within the biliary tract, and cholangitis constitute the most frequent clinical consequences of frank intrabiliary rupture (10). Acute or chronic pancreatitis $(20,21)$, acute cholecystitis or even biliary cirrhosis (6) has also been reported. Symptoms are mostly nonspecific, while in 5\% of patients intrabiliary ruptures are asymptomatic (4,6,9,22-25). Upper abdominal pain, jaundice and fever were the presenting symptoms in our patient, and mild, right, upper quadrant tenderness was found despite her advanced age.

Although suspicion is high in endemic areas, diagnosis of intrabiliary rupture of a hydatid cyst in nonendemic areas is usually not straightforward. Trying to establish early diagnosis of certain clinical predictors has been proposed. A history of nausea and vomiting, a serum alkaline phosphatase level greater than $144 \mathrm{U} / \mathrm{L}$, a total bilirubin level greater than $13.6 \mu \mathrm{mol} / \mathrm{L}$ and a cyst diameter greater than $14.5 \mathrm{~cm}$ seem to all be independent risk factors for occult rupture. On the other hand, a type IV cyst after secondary bacterial infection, suggestive ultrasonographic findings (irregular linear echogenic structures without acoustic shadowing in the bile duct and/or the dilated biliary system), a cyst diameter larger than $10.5 \mathrm{~cm}$, jaundice found on physical examination and a history of jaundice seem to all be independent clinical factors for frank rupture (25). Preoperative diagnosis of a frank rupture is important because by performing ERC and ES, an unnecessary CBD exploration can be avoided; complete drainage of the cyst may even postpone surgery (25). Otherwise, the CBD should be examined with intraoperative cholangiography.

The diagnosis of intrabiliarily ruptured hydatid cysts has been assisted by imaging and laboratory tests. Although these tests were proven to be ineffective in detecting occult rupture, certain findings in the United States raise an essential clue to the diagnosis of frank rupture with obstruction. Echogenic material, without posterior acoustic shadowing in the extrabiliary ducts, is a finding implying the presence of intracystic material (26). The cyst may also be depicted as smaller after rupture $(10,17)$, with the extrahepatic biliary tract dilated (70\%) $(22,24,27)$ and sludge-like hydatid material possibly apparent in the biliary tract ( $53 \%$ to $80 \%$ ), while in $20 \%$ to $47 \%$ of cases the communication is visualized with dilated biliary radicle(s) with a conical appearance near the main cyst $(17,22,24,28-30)$. An abdominal CT scan may reveal a dilated CBD with low attenuation intraluminal material, suggesting the presence of hydatid sand and cysts $(1,31)$. Cyst wall discontinuity followed by bile duct dilation with intraluminal hydatid debris, the highly suggestive direct sign of rupture, is identified in approximately $75 \%$ of cases $(10,29)$. CT may demonstrate high attenuation material passing through the defect of the cystic wall and filling up of the intrahepatic biliary radicles or $\mathrm{CBD}$, or the presence of intracystic gas that is thought to be due to biliary reflux of gas into the cyst $(10,32)$. The combination of the abdominal CT scan and the American findings helps to improve diagnostic accuracy (10,29). Recently, magnetic resonance imaging has proven to be a useful noninvasive diagnostic adjunct in cases of intrabiliary rupture, whereas CT scan and ultrasound results are not conclusive (33). A breach in the rim of the wall with extrusion of cystic contents constitutes a direct diagnostic sign, while fluid levels, presence of air and changes in signal intensity comprise indirect signs $(26,34)$. In cases of intrabiliary rupture, direct hyperbilirubinemia, hyperamylasemia and increased white blood cell counts are usually present but are nonspecific, while eosinophilia is found in $30 \%$ to $40 \%$ of cases $(6,22,24)$. Elevated antibody titres against echinococcal antigens are reported in approximately $80 \%$ of cases (22).

If a cystobiliary connection could not be suspected preoperatively, certain intra- and postoperative findings raise suspicion, leading to CBD exploration: bile-stained cystic fluid, visualized bile leak orifice and CBD enlargement, as well as substantial bile drainage from the cavity drains (13). When an intrabiliary rupture is diagnosed pre- or intraoperatively, suturing the orifice (if seen) should be incorporated with the conventional techniques of cystic evacuation, removal of the germinative layer and disinfection of the cystic cavity (35). If cystic material is suspected to be contained in a normal calibre choledochus, then choledochotomy, evacuation of cystic debris, irrigation using hypertonic saline and T-tube drainage have proven to be sufficient. If CBD enlargement has been already established, choledochoduodenostomy is preferable (36). Roux-en-Y hepaticojejunostomy is reserved if bile duct stricture has developed. Recently, open ES has also been used. Even cystojejunostomy has been applied, albeit with the risk of jaundice and cholangitis caused by cystic content drainage into the biliary tract (13)

If preoperative diagnosis of intrabiliarily ruptured hydatid cyst has been established or highly suspected, ERC with ES is performed to extract retained daughter cysts from the biliary tract. In conjunction with or without nasobiliary stent application, the obstructed CBD is evacuated by using a Dormia basket or a biliary occlusion balloon $(7,37,38)$, thereby avoiding its exploration during surgery. In addition, postoperative biliary fistula formation can be prevented by draining the cyst cavity (35). Moreover, scattered cases of definitive treatment of obstructive jaundice after intrabiliary rupture using endoscopy have been reported. Thus, by achieving a detection rate of $86.6 \%$ to $100 \%$, ERC has been rendered the 'gold standard' in the assessment of intrabiliary rupture $(16,17,22,24)$. Certain findings, such as edematous hyperemic Vater's papilla with hydatid material protruding $(17,22,24,39-41)$, may lead to the diagnosis. Cystobiliary fistulas, biliary dilation, and daughter vesicles and hydatid material in biliary ducts as filling defects may also be shown. Extrinsic compression of the bile duct is less frequent, while distal stenosis, pancreatic channel dilation or cysts in the channel are rare findings (17,24,39-41). Hydatid membranes or daughter cysts in the biliary tract may resemble gallstones in cholangiography. However, the leaf-like irregular aspect of the membrane and the weak regular contrast of daughter cysts assist in the diagnosis (17). Depiction of a cut intrahepatic duct, occluded by a daughter cyst, is the most 
definite finding $(22,24,39,40,42)$. In 'silent' rupture, visualization of the ruptured cyst is practically impossible because the radio-contrast agent cannot pass through the multiple but small openings. In frank rupture, a possible failure to determine the communication is attributed to the impaction of hydatid material at the site of perforation (22). Through ERC, even evacuation of the mother cyst can be performed if a nasobiliary tube is placed followed by irrigation with hypertonic saline (40). After initial management of the intrabiliary rupture with ERC, $75 \%$ of cases had to undergo elective surgery, while in $25 \%$ of cases no further intervention was required $(16,17,21,37,41,43-48)$. Anthelminthic therapy was shown to be effective as an adjunct to endoscopic treatment $(16,49)$.

If an intrabiliary rupture is not preoperatively suspected and/or intraoperatively overlooked, postoperative biliary fistulas are unavoidable, constituting the most frequent complication after surgery for hepatic hydatid disease. Infection and/or abscess formation may occur after colonization of the ruptured cavity through the external cystobiliary fistula by common intra-abdominal pathogens (10). Moreover, in occult rupture, lack of symptoms and dilation of the CBD lead to a difficult preoperative diagnosis. Thus, if not frequently diagnosed intraoperatively, occult rupture may cause postoperative biliary leakage resulting in external cystobiliary fistulas $(38,49,50)$. On the contrary, frank rupture, causing intermittent or complete obstruction, can usually be preoperatively diagnosed. Although external biliary fistulas often close spontaneously, they can persist in $(3,8-27) 5 \%$ of patients, $11 \%$ of whom will develop ascending cholangitis (37). Replacement of daily electrolyte and fluid losses has proven to be sufficient in low-output fistulas (less than $300 \mathrm{~mL}$ daily output) (35). On the other hand, an early, high-output fistula postoperatively, predicts a nonspontaneously resolving fistula, possibly due to the impact of hydatid material into the $\mathrm{CBD}$, or to frank-type communication. In these cases, early ERC with ES postoperatively is proposed because delay may cause fistula persistence and infectious complications (51). Moreover, in the case of overlooked persistent cystobiliary fistulas, ES should be of great benefit because it facilitates continuous biliary flow by decreasing the duodenobiliary pressure gradient $(40,45,52-55)$. If a nasobiliary catheter is placed, it constantly drains the biliary tract while allowing monitoring of the fistula by cholangiography. As an alternative to ES, an endoprosthesis may be placed and later withdrawn when external drainage ceases $(38,56-60)$. ERC which is a

\section{REFERENCES}

1. McManus DP, Zhang W, Li J, Bartley PB. Echinococcosis. Lancet 2003;362:1295-304.

2. Daali M, Fakir Y, Hssaida R, Hajji A, Hda A. [Hydatid cysts of the liver opening in the biliary tract. Report of 64 cases.] Ann Chir 2001; 126:242-5.

3. Lygidakis NJ. Diagnosis and treatment of intrabiliary rupture of hydatid cyst of the liver. Arch Surg 1983;118:1186-9.

4. Propatoridis J. The rupture of the echinococcus cyst of the liver into the bile ducts. Am J Gastroenterol 1954;21:219-29.

5. al-Hashimi HM. Intrabiliary rupture of hydatid cyst of the liver. Br J Surg 1971;58:228-32.

6. Kattan YB. Intrabiliary rupture of hydatid cyst of the liver. Br J Surg 1975;62:885-90.

7. Reddy DN, Sriram PV, Rao GV. Endoscopic diagnosis and management of tropical parasitic infestations. Gastrointest Endosc Clin N Am 2003;13:765-73,x-xi

8. Koksal N, Muftuoglu T, Gunerhan Y, Uzun MA, Kurt R. Management of intrabiliary ruptured hydatid disease of the liver. Hepatogastroenterology 2001;48:1094-6. minimally invasive procedure may obviate reoperation. The success rate is reported to be $70 \%$ to $100 \%$, with an overall rate of fistula closure of $81 \%$ in 10 to 20 days (61). Controversy exists whether fistulae daily output or concomitant hydatid material in the biliary tract influences the time required for complete closure (51).

Thus, endoscopy is a modality serving both diagnostic and therapeutic aims. Preoperative ERC permits evaluation in the case of cholangitis or obstruction, possibly resulting in a cure in cases of frank intrabiliary rupture, or in the present case, and if combined with ES decreases the incidence of postoperative external fistulas. On the other hand, ERC postoperatively may clarify causes of ongoing or recurrent symptoms, or laboratory abnormalities and may resolve obstruction or cholangitis due to residual material in biliary ducts, while providing management of postoperative external biliary fistulae (17). Using an endoscopic approach in our patient, complete evacuation of the biliary tree from the obstructing daughter cysts, as well as irrigation with hypertonic saline, were achieved. Regarding the patient's rapid clinical improvement, as well as high surgical risk, no further intervention was considered necessary. Thus, endoscopy, although sparsely used as monotherapy, proved to be therapeutic (9). We advocate for ERC with ES to be used in intrabiliarily ruptured hydatid liver cysts based on the sparse published evidence regarding safety, and short- and long-term efficacy $(16,21,37,40,41,44-46)$. Alleviating obstruction and irrigating the biliary tree as well as the mother cyst, endoscopy may minimize the need for surgery.

Recently the treatment of hydatid liver disease was reviewed extensively, it was concluded that the level of evidence available on the treatment of complicated hydatid liver disease was low (62). Thus, it was evident that endoscopic procedures should at least be a therapy arm in future trials evaluating the available modalities for the treatment of ruptured hydatid liver disease. ERC should be a procedure of choice for acute complications such as cholangitis and obstruction, pre- and postoperatively, allowing surgery, if necessary, to be performed on an elective basis.

\section{CONCLUSION}

ERC with ES proved to be a choice offering excellent immediate and short-term postprocedure results. Thus, it may be proposed alternatively, especially if surgical risk is high and clinical benefit adequate.
9. Guidelines for treatment of cystic and alveolar echinococcosis in humans. WHO Informal Working Group on Echnococcosis. Bull World Health Organ 1996;74:231-42.

10. Lewall DB, McCorkell SJ. Rupture of echinococcal cysts: Diagnosis, classification, and clinical implications. AJR Am J Roentgenol 1986;146:391-4.

11. Yalin R, Aktan AO, Yegen C, Dosluoglu HH. Significance of intracystic pressure in abdominal hydatid disease. Br J Surg 1992;79:1182-3.

12. Tsitouridis J, Kouklakis G, Tsitouridis K, Melidis D, Krokos N, Emmanoyilidoy M. Intrabiliary obstruction due to ruptured hepatic hydatid cyst: Evaluation with computed tomography and magnetic resonance imaging. Dig Endosc 2001;13:7-12.

13. Bedirli A, Sakrak O, Sozuer EM, Kerek M, Ince O. Surgical management of spontaneous intrabiliary rupture of hydatid liver cysts. Surg Today 2002;32:594-7.

14. Kornaros SE, Aboul-Nour TA. Frank intrabiliary rupture of hydatid hepatic cyst: Diagnosis and treatment. J Am Coll Surg 1996;183:466-70. 
15. Kattan YB. Intrabiliary rupture of hydatid cyst of the liver. Ann R Coll Surg Engl 1977;59:108-14.

16. Becker K, Frieling T, Saleh A, Haussinger D. Resolution of hydatid liver cyst by spontaneous rupture into the biliary tract. J Hepatol 1997:26:1408-12

17. Ozaslan E, Bayraktar Y. Endoscopic therapy in the management of hepatobiliary hydatid disease. J Clin Gastroenterol 2002;35:160-74.

18. Macris GJ, Galanis NN. Rupture of echinococcus cysts of the liver into the biliary ducts: Report of nine cases. Am Surg 1966;32:36-44.

19. Harris JD. Rupture of hydatid cysts of the liver into the biliary tracts. Br J Surg 1965;52:210-4.

20. Medina E, Orti E, Canelles P, Calvo MA, Molina E. [Complicated hepatic hydatid cyst and acute pancreatitis. Value of ERCP and treatment with endoscopic sphincterotomy.] Rev Esp Enferm Dig 1990;78:315-8.

21. Saez-Royuela F, Yuguero L, Lopez-Morante A, Perez-Alvarez JC, Martin-Lorente JL, Ojeda C. Acute pancreatitis caused by hydatid membranes in the biliary tract: Treatment with endoscopic sphincterotomy. Gastrointest Endosc 1999;49:793-6.

22. Zargar SA, Khuroo MS, Khan BA, Dar MY, Alai MS, Koul P. Intrabiliary rupture of hepatic hydatid cyst: Sonographic and cholangiographic appearances. Gastrointest Radio1 1992;17:41-5.

23. Stavorovsky M, Wientroub S, Iellin A, Papo J. Rupture of a hydatid cyst of the liver into the biliary tract. Int Surg 1977;62:603-8

24. Van Steenbergen W, Fevery J, Broeckaert L, et al. Hepatic echinococcosis ruptured into the biliary tract. Clinical, radiological, and therapeutic features during five episodes of spontaneous biliary rupture in three patients with hepatic hydatidosis. J Hepatol 1987:4:133-9

25. Atli M, Kama NA, Yuksek YN, et al. Intrabiliary rupture of a hepatic hydatid cyst: Associated clinical factors and proper management. Arch Surg 2001;136:1249-55.

26. Mendez Montero JV, Arrazola Garcia J, Lopej Lafuente J, Antela Lopez J, Mendez Fernandez R, Saiz Ayala A. Fat-fluid level in hepatic hydatid cyst: A new sign of rupture into the biliary tree? AJR Am J Roentgenol 1996;167:91-4.

27. Nagler A, Enat R, Brenner B, Israel O, Argov S. Hydatid cyst of the liver rupturing into the biliary tract - mimicking acute cholecystitis on hepatobiliary scanning. Am J Gastroenterol 1985;80:819-21.

28. Marti-Bonmati L, Menor Serrano F. Complications of hepatic hydatid cysts: Ultrasound, computed tomography, and magnetic resonance diagnosis. Gastointest Radiol 1990;15:119-25.

29. Marti-Bonmati L, Menor F, Ballesta A. Hydatid cyst of the liver: Rupture into the biliary tree. AJR Am J Roentgenol 1988;150:1051-3.

30. Ascenti G, Scribano E, Loria G, Vallone A, Pandolfo I, Gaeta M [Computerized tomography in the assessment of obstructive jaundice caused by hepatic hydatid cysts.] Radiol Med (Torino) 1995;89:804-8.

31. Subramanyam BR, Balthazar EJ, Naidich DP. Ruptured hydatid cyst with biliary obstruction: Diagnosis by sonography and computed tomography. Gastrointest Radiol 1983;8:341-3.

32. Pedrosa I, Saiz A, Arrazola J, Ferreiros J, Pedrosa CS. Hydatid disease: Radiologic and pathologic features and complications. Radiographics 2000;20:795-817.

33. Kumar R, Reddy SN, Thulkar S. Intrabiliary rupture of hydatid cyst: Diagnosis with MRI and hepatobiliary isotope study. $\mathrm{Br} J$ Radiol 2002;75:271-4

34. Little AF, Lee WK, Mathison K. MR cholangiography in the evaluation of suspected intrabiliary rupture of hepatic hydatid cyst. Abdom Imaging 2002;27:333-5.

35. Yagci G, Ustunsoz B, Kaymakcioglu N, et al. Results of surgical, laparoscopic, and percutaneous treatment for hydatid disease of the liver: 10 years experience with 355 patients. World J Surg 2005;29:1670-9.

36. Alper A, Ariogul O, Emre A, Uras A, Okten A. Choledochoduodenostomy for intrabiliary rupture of hydatid cysts of liver. Br J Surg 1987;74:243-5.

37. Rodriguez AN, Sanchez del Rio AL, Alguacil LV, De Dios Vega JF, Fugarolas GM. Effectiveness of endoscopic sphincterotomy in complicated hepatic hydatid disease. Gastrointest Endosc 1998;48:593-7.

38. Tekant Y, Bilge O, Acarli K, Alper A, Emre A, Ariogul O. Endoscopic sphincterotomy in the treatment of postoperative biliary fistulas of hepatic hydatid disease. Surg Endosc 1996;10:909-11.
39. Shemesh E, Friedman E. Radiologic and endoscopic appearance of intrabiliary rupture of hydatid liver disease. Digestion 1987;36:96-100.

40. al Karawi MA, Yasawy MI, el Shiekh Mohamed AR. Endoscopic management of biliary hydatid disease: Report on six cases. Endoscopy 1991;23:278-81.

41. Hilmioglu F, Karincaoglu M, Yilmaz S, et al. Complete treatment of ruptured hepatic cyst into biliary tract by ERCP. Dig Dis Sci 2001;46:463-7.

42. Moreira Vicente VF, Merono Garcia E, Simon Marco MA. Endoscopic retrograde cholangiography (ERCP) and complicated hepatic hydatid cyst in the biliary tract. Endoscopy 1984;16:124-6.

43. Spiliadis C, Georgopoulos S, Dailianas A, Konstantinidis A, Rimikis M, Skandalis N. The use of ERCP in the study of patients with hepatic echinococcosis before and after surgical intervention. Gastrointest Endosc 1996;43:575-9.

44. Shemesh E, Klein E, Abramowich D, Pines A. Common bile duct obstruction caused by hydatid daughter cysts - Management by endoscopic retrograde sphincterotomy. Am J Gastroenterol 1986;81:280-2

45. Akkiz H, Akinoglu A, Colakoglu S, Demryurek H, Yagmur O. Endoscopic management of biliary hydatid disease. Can J Surg 1996;39:287-92.

46. Al Karawi MA, Mohamed AE, Yasawy I, Haleem A. Non-surgical endoscopic trans-papillary treatment of ruptured echinococcus liver cyst obstructing the biliary tree. Endoscopy 1987;19:81-3.

47. Dziri C, Paquet JC, Hay JM, et al. Omentoplasty in the prevention of deep abdominal complications after surgery for hydatid disease of the liver: A multicenter, prospective, randomized trial. French Associations for Surgical Research. J Am Coll Surg 1999;188:281-9.

48. Ulualp KM, Aydemir I, Senturk H, et al. Management of intrabiliary rupture of hydatid cyst of the liver. World J Surg 1995;19:720-4; discussion 728

49. Iscan M, Duren M. Endoscopic sphincterotomy in the management of postoperative complications of hepatic hydatid disease. Endoscopy 1991;23:282-3.

50. Vignote ML, Mino G, de la Mata M, de Dios JF, Gomez F. Endoscopic sphincterotomy in hepatic hydatid disease open to the biliary tree. Br J Surg 1990;77:30-1.

51. Dolay K, Akcakaya A, Soybir G, et al. Endoscopic sphincterotomy in the management of postoperative biliary fistula. A complication of hepatic hydatid disease. Surg Endosc 2002;16:985-8.

52. Zaouche A, Haouet K, Jouini M, El Hachaichi A, Dziri C. Management of liver hydatid cysts with a large biliocystic fistula: Multicenter retrospective study. Tunisian Surgical Association. World J Surg 2001;25:28-39.

53. Erzurumlu K, Dervisoglu A, Polat C, Senyurek G, Yetim I, Hokelek M. Intrabiliary rupture: An algorithm in the treatment of controversial complication of hepatic hydatidosis. World J Gastroenterol 2005;11:2472-6.

54. Saritas U, Parlak E, Akoglu M, Sahin B. Effectiveness of endoscopic treatment modalities in complicated hepatic hydatid disease after surgical intervention. Endoscopy 2001;33:858-63.

55. Ponchon T, Bory R, Chavaillon A. Endoscopic retrograde cholangiography and sphincterotomy for complicated hepatic hydatid cyst. Endoscopy 1987;19:174-7.

56. Dumas R, Le Gall P, Hastier P, Buckley MJ, Conio M, Delmont JP. The role of endoscopic retrograde cholangiopancreatography in the management of hepatic hydatid disease. Endoscopy 1999;31:242-7.

57. Bilsel Y, Bulut T, Yamaner S, et al. ERCP in the diagnosis and management of complications after surgery for hepatic echinococcosis. Gastrointest Endosc 2003;57:210-3.

58. Galati G, Sterpetti AV, Caputo M, et al. Endoscopic retrograde cholangiography for intrabiliary rupture of hydatid cyst. Am J Surg 2006;191:206-10.

59. Giouleme O, Nikolaidis N, Zezos P, et al. Treatment of complications of hepatic hydatid disease by ERCP. Gastrointest Endosc 2001;54:508-10.

60. Chautems R, Buhler LH, Gold B, et al. Surgical management and long-term outcome of complicated liver hydatid cysts caused by Echinococcus granulosus. Surgery 2005;137:312-6.

61. Simsek H, Ozaslan E, Sayek I, et al. Diagnostic and therapeutic ERCP in hepatic hydatid disease. Gastrointest Endosc 2003;58:384-9.

62. Dziri C, Haouet K, Fingerhut A. Treatment of hydatid cyst of the liver: Where is the evidence? World J Surg 2004;28:731-6. 


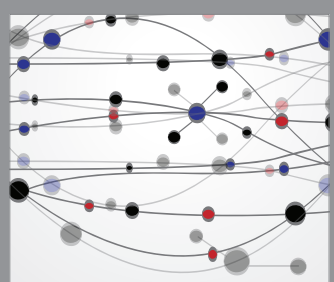

The Scientific World Journal
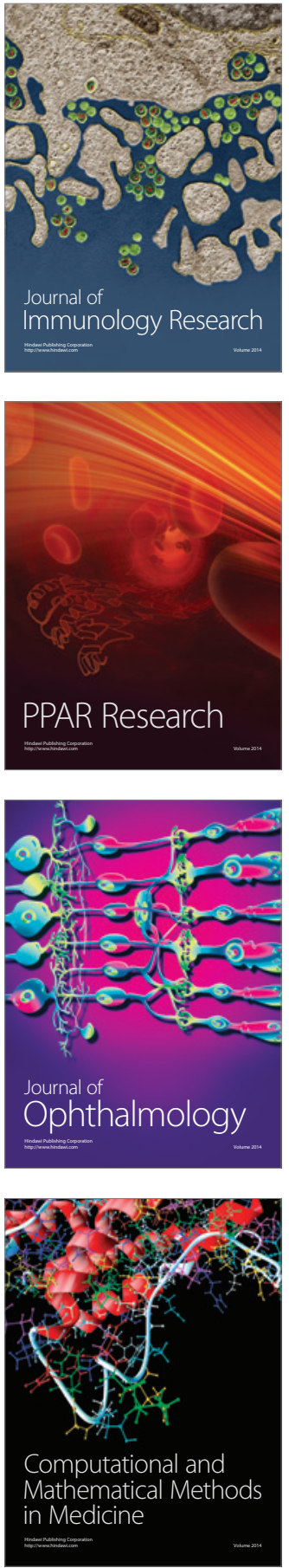

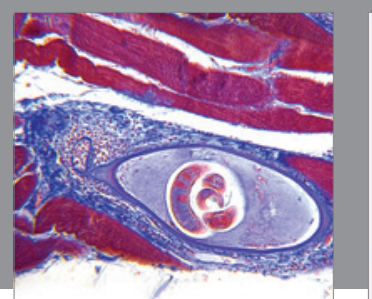

Gastroenterology Research and Practice

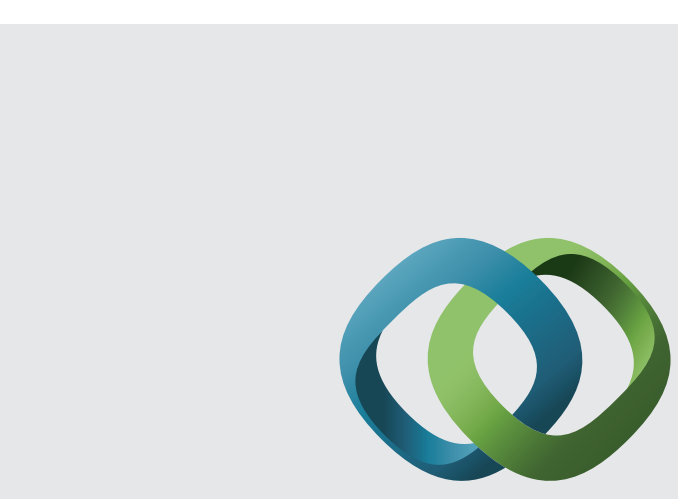

\section{Hindawi}

Submit your manuscripts at

http://www.hindawi.com
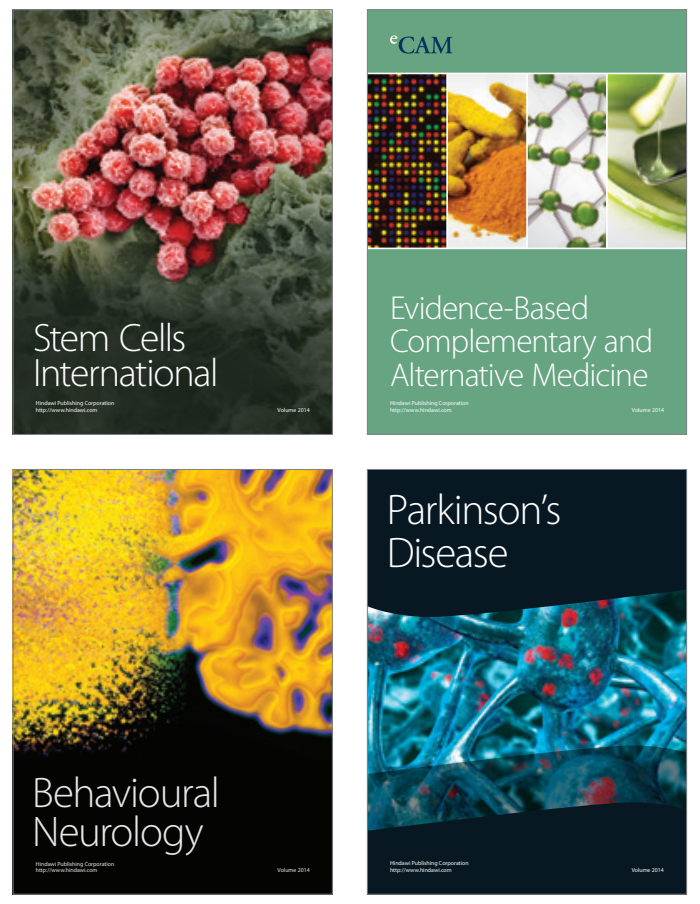
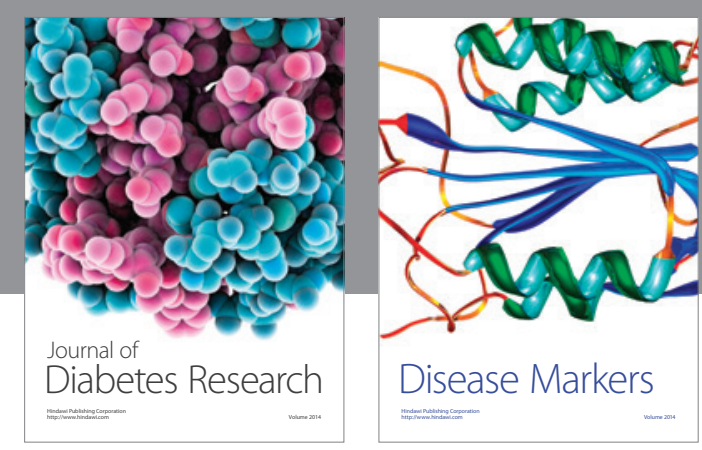

Disease Markers
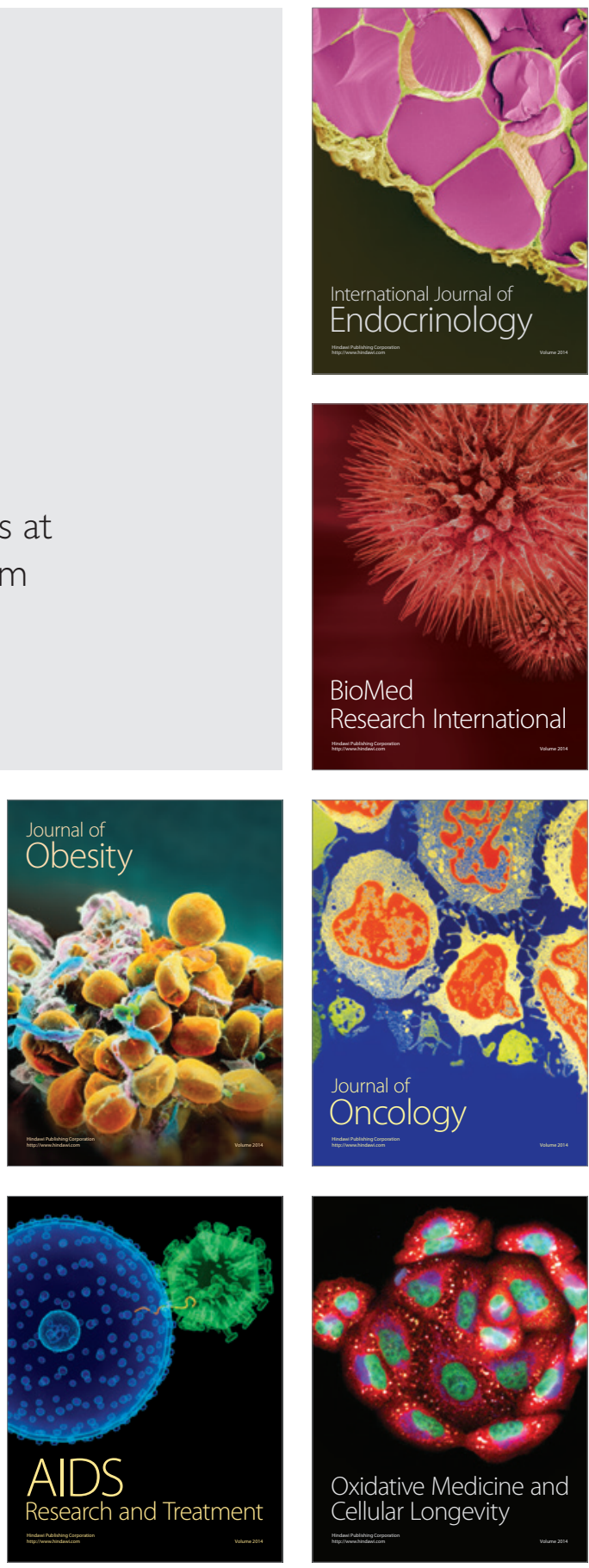